\title{
Examining Construct Validation of the English Language Teachers Competency Test
}

\author{
Reza Pishghadam (Corresponding author) \\ English Department, Ferdowsi University of Mashhad \\ PO box 9177948974, Park Square, Ferdowsi University, Mashhad, Iran \\ Tel: 0098-915-307-3063Email: rpishghadam@yahoo.com \\ Farnoush Khosropanah \\ English Department, Ferdowsi University of Mashhad \\ PO box 9177948974, Park Square, Ferdowsi University, Mashhad, Iran \\ Email: farnooshkhosropanah@yahoo.com
}

Received: January 25, 2011 Accepted: February 28, 2011 doi:10.5539/ies.v4n3p194

\begin{abstract}
The major purpose of this study was to examine the construct validity of English Language Teachers Competency Test (ELT-CT) designed by Pishghadam, Baghaei and Shahriari (2010). In this study, Exploratory Factor Analysis (EFA) was used to examine the construct validity of the test. The results have shown that the underlying factors of the test are what the test-designer claims to be. The results have revealed that ten factors represent the underlying structure of ELT-CT. Finally, statistical results were discussed, and implications were provided in the context of English language teaching.
\end{abstract}

Keywords: Teacher cognition, Teacher competency tests, Teacher success, Construct validity

\section{Introduction}

An educational system should have different factors to be considered successful; these factors may vary from the facilities that an educational system can provide up to having competent teachers. Undoubtedly, competent teachers can guarantee success of any educational system. Swandee (1995) considers teaching as a two-way relationship between students and the teacher, believing that what students learn, depends mostly on the teacher and on the teacher's commitment towards their job. According to Brown (2007), teachers can be agents of change, change of competition to cooperation, weakness to strength, leading students to more success.

Rice (2003) considers teaching as a complicated action which is influenced by teacher's characteristics, in which students' success can be predicted based on the teacher's capabilities. Baydala, Rasmussen and Sherman (2008) also state that teacher factors can have profound impacts on various outcome measures. Teachers who demonstrate patience and knowledge of intervention techniques can have a positive impact on students' success. In the same vein, Dilmac (2009) claims that teachers need the possession of certain characteristics if they want to be successful and Hamdan, Ghafar, and Li (2010), hold that some of these characteristics can be competence and standards that might go quite beyond the standards and principles which are accepted worldwide.

As mentioned, teachers have a very important role in any educational system and due to this important role, we should be very cautious in selecting the most influential and competent teachers. One of the best ways to select competent teachers is through using Teachers Competency Tests (TCTs). Mehrens (1987) states that TCTs are the tests that can help us to separate competent teachers from incompetent ones and help us to select and employ the most competent teachers. TCTs are used to control the entry of students into teacher training programs, certify successful completion of a teacher training program, control initial certification or licensure of teachers and informing decisions regarding re-certification or promotion of experienced teachers. The motivating factor behind TCTs is that we do not want incompetent teachers. Therefore, several different teacher competency tests have been designed around the world. Countries like United States, England and Canada and also India are using TCTs. To name a few of TCTs which are currently in use, we can mention: National Teachers Examinations (NTE), Pre-Professional Skills Test (PPST) and also tests which were developed by Educational Testing Service for each state in the US (Mehrens, 1987). Moyer-Pockenham, Bolyard, Kitsantas, and Oh (2008) also examined TCTs being 
used to document mathematics and science teacher quality characteristics. However, to our knowledge, only one test has been developed by Pishghadam, Baghaei, and Shahriari (2010) in the context of foreign language learning in Iran to measure the competency knowledge of English language teachers. Therefore, our purpose in this study is to examine the construct validity of the test.

\section{Theoretical Framework}

TCTs are used to delve into teacher's cognition. According to Borg (2003) teacher's cognition refers to what teachers may know and reflect how this can influence their behavior and actions as they occur in the classroom, and that there is an interaction between teacher thinking and practice and the context in which teaching happens and the teacher's own previous learning experiences also have a very important role. Strom and Tymofyeyev (2004) believe that the need for competency testing arises every time when a recruiter interviews a new candidate for a job position, and in general it can be used to identify the most appropriate people for different jobs.

Hamdan, Ghafar, and Li (2010), did a study to find out the level of teaching competency of school teachers of the district of Johor Bahru Malaysia. The authors tried to find out the teachers competency on their teaching skills, effectiveness, professional characteristics and classroom management. The results of this study showed that the teachers had high level of competency in teaching. The results showed that teachers had high competency in the four mentioned scales. The study also showed that there was no relationship between teaching competency and teachers' academic achievements. There was a relationship between teaching competency and the teachers' gender and the female teachers were found to be more competent than the male teachers. There was also no relationship between teaching competency and ethnicity of the teachers. So, in their study the authors were to find out if the teachers of Malaysia had the necessary competency needed to be good teachers and they found out that they were actually quite competent according to the factors listed in the questionnaire.

Penn-Edwards (2010) also worked on the issue of teacher competency. The author conducted a survey with first year Education students at the Queensland University and tried to find out the level of competency in literacy which was expected for teachers in schools. So, the author tried to examine the amount and kind of literacy competency needed for an English teacher. In order to do that the researcher designed and distributed a Likert-scale survey among 309 Education students. Eight aspects of literacy were identified and the students had to indicate the level of skill (from 1 to 5) they believed a competent teacher should have. These eight literacy aspects were: verbal and nonverbal competencies like communicating, informing and persuading through debate and presentation, reading and listening skills, visual skills like graphics and composition, genre knowledge, structure, grammar, spelling competency and ICT and computing skills. The results of the study showed that the students thought that a competent English teacher should have a level 4 or 5 of all of these literacy competencies.

In another study, Pishghadam et al. (2010) designed a special teacher competency test just for English teachers which can mostly be used for the employment as well as for the licensure and certification purposes. The author tried to validate the test (ELT-CT) against language teachers in private institutes in Iran. His method of analysis was Rasch measurement and the results showed that all items contribute towards the definition of a unified construct of teacher competency. Since this test is a novel one in ELT, it seems that its validity must be espoused and confirmed by more analysis.

\section{Purpose of the Present Study}

The value of any good test is that it exhibits a great amount of validity. The more we validate a test with different procedures, the more trust we can put in its findings and results. With that in mind, in this study we intended to substantiate the construct validity of ELT-CT which has been designed by Pishghadam et al. (2010) by using Exploratory Factor Analysis (EFA). Therefore, the study investigates these research questions:

i. What factors are measured by ELT-CT?

ii. Does each factor of ELT-CT show acceptable amount of reliability?

\section{Method}

\subsection{Participants}

A sample of 120 people participated in this study, comprised of 85 females and 35 males between the ages of 20 and $50(\mathrm{M}=27.2)$. All of the participants were English language teachers who were university students or university graduates. Most of them were majoring in three majors: English Literature $(\mathrm{N}=30)$, English Teaching $(\mathrm{N}=35)$, and English Translation $(\mathrm{N}=30)$, and a few of them were majoring in other university majors $(\mathrm{N}=25)$. The participants were either students or holders of BA $(\mathrm{N}=102)$ and also students or holders of MA $(\mathrm{N}=18)$ in their own majors. All our participants were instructing English in 4 different language institutes in Mashhad, a city in Iran. 


\subsection{Instrumentation}

ELT-CT has 61 items with the reliability of 0.64 which has been calculated with Cronbach alpha. ELT-CT has been validated by using Rasch analysis version 3.66. Fit statistics show that all items fit the Rasch model following the criteria suggested by Bond \& Fox (2007). Items which do not fit the Rasch model have outfit and infit mean square indices outside the acceptable range of $0.70-1.30$. None of the items of ELT-CT have infit and outfit indices outside the acceptable boundary. It takes one hour to take the test.

\subsection{Procedures}

In this study, the authors tried to validate the ELT-CT by the use of EFA, pinpointing what are the real underlying constructs of this test. In order to achieve this purpose, the test was distributed among English language teachers and then EFA was used to determine the underlying factors. The internal consistency of the whole questionnaire was measured with the Cronbach Alpha reliability estimate. Moreover, using Cronbach Alpha, the reliability of each factor constructing the validated test was also examined. To validate the questionnaire, first Principal Component Analysis (PCA) extracted the underlying factors by calculating the eigenvalues of the matrix greater than 1.0. The Scree test was used in order to decide about the number of factors to retain for rotation. For conducting factor rotation, Varimax (orthogonal rotation) with Kaiser Criterion was used. The result was a rotated component matrix and a transformation matrix. The rotated component matrix indicated the variables loaded on each factor so that the researchers could come up with the new factors.

\section{Results}

\subsection{Reliability of the Scale}

Cronbach Alpha estimated the reliability of the whole items as 0.77. All of the ten factors yielded moderate reliability estimates ranging from 0.43 to 0.67 except factors 8 and 9 which showed low reliability estimates, which can be justified by the low number of items in these factors (see Table 1).

\subsection{Construct Validity}

The Factorability of the intercorrelation matrix was measured by two tests: Kaiser-Meyer-Olkin test of Sampling Adequacy (KMO) and Bartlett's Test of Sphericity. The results obtained from the two tests revealed that the factor model was appropriate (see Table 2).

The construct validity of the ELT-CT was examined through EFA. PCA extracted 23 factors with eigenvalues greater than 1.0. The results obtained from the Scree Test indicated that a ten-factor solution might provide a more suitable grouping of the items in the questionnaire (see Figure 1).

The researchers, then, inspected orthogonal rotation. The result of Varimax with Kaiser Normalization was a rotated component matrix. The results of this analysis are shown in Table 3. The results indicated that the first factor consisted of 12 items. The second factor consisted of 6 items. Factor 3 consisted of 9 items. Factor 4 consisted of 9 items and factor 5 consisted of 5 items, factor 6 consisted of 4 items, factor 7 consisted of 4 items, factor 8 consisted of 2 items, factor 9 consisted of 3 items and items 33, 37, 50 and 53 were in factor 10. The total number of items was 61 .

Finally, the researchers analyzed the items comprising each factor and named the ten factors as Feedback \& Flexibility, Teaching methodology, Learning boosters, Motivation, Sociology of language teaching \& learning, EQ, NLP, Students' self-esteem, Thinking and Face saving acts (FSA). Items representing each factor are displayed in Table 4, and the validated test is given in Appendix.

\section{Discussion}

This study sought to determine the reliability and validity of the English Language Teachers Competency Test when examined with EFL students. The results of this analysis were used to name each factor. The reasons for the selection of such names are explained below.

\section{Feedback \& flexibility}

Feedback \& Flexibility is the label for the first factor which consists of 13 items. As it is shown in Appendix, items $6,7,11,17,18,19,23,25,26,27,32,48$, and 49 measure teachers' amount of flexibility and the teachers' ability and method of giving feedback. Giving feedback is to check students for mistakes, helping them to avoid them and flexibility is a characteristic of teachers who are more democratic in their classes and let their students be involved in decision-making process in class. Items $6,7,11,25,26,27,32,48$, measure the teachers' flexibility in their class management, teaching methodology and also syllabus design. Items 17, 18, 19, 23, 49, measure teachers' ability to give appropriate feedback. 


\section{Teaching methodology}

The second factor is called Teaching methodology which refers to the methods and the techniques that teachers use in their classes. This factor consists of 6 items. Item 24 refers to the method of teaching writing. Items 31 and 41 refer to the teaching methodology in general and specifically to teaching through interaction and communicative method of teaching. Item 42 refers to the teachers' method for managing the class and their relationship with their students. Item 44 refers to the teachers' method of conducting discussion and also to the use of grouping of students. Item 60 refers to the method of teaching language skills in general.

\section{Learning boosters}

Factor 3 which is named Learning Boosters is comprised 9 items. Learning boosters are the factors that can increase learning, consisting of many different factors, from class management techniques to emotional relationship that the teacher might build with their students. Item 1 helps them learn better and boost learning if we use it when necessary. Item 3 refers to the situations when students do not get disappointed even if they get a bad score because there are no numbers. Item 8 refers to the techniques to make the class a bit more informal. Item 35 refers to the ways that the teachers let students feel that their opinions are also important for the teacher; this can make learners become motivated and boost their learning. Item 38 refers to the teachers' class management techniques which can boost learning. Items 45 and 52 refer to teaching methodology and the use of group work to keep the students active. Item 51 is about the way teacher presents materials in class and what words he/she can use to boost learning. Item 58 refers to the teachers' choice of activity and the type of activities that can boost learning.

\section{Motivation}

Motivation is the label selected by the researchers for the fourth factor of the scale which includes 9 items. Motivation refers to the eagerness to do something. L2 motivation as a very important factor in learning a language provides the primary impetus to start learning L2 (Dornyei, 2005). Items 10, 14, 22, 36, 40 and 55 refer to the factors that can keep the learners motivated. Item 43 refers to what teachers can do to keep learners motivated and avoid repetition in class. Items 56 and 57 are to keep the researching spirits in the learners, jacking up learners.

\section{Sociology of language teaching and learning}

The fifth factor of the questionnaire is named as Sociology of Language Teaching and Learning which is referred to as the social relationships in the class between the teachers and the students and also among the students. This factor consists of 6 items. Item 4 refers to the teacher's responsibility for increasing the students' awareness of social and cultural differences between the speakers of different languages. Item 12 refers to the teachers' knowledge and understanding of social and cultural capitals in each class. Items 21 and 30 measure the teachers' awareness of the social class differences that exist among the learners. Item 28 refers to a postmodern notion which claims that there are more than one way to solve a problem. Item 34 also refers to the teachers' awareness of cultural differences.

\section{$E Q$}

The sixth factor which is referred to as EQ is consisting of 4 items. This factor refers to the teachers' ability to make relationships with the learners. Items 5 and 13 measure the teachers' ability to build relationship with the learners. Item 16 refers to the teachers' ability to understand and know their learners. Item 39 measures the teachers' knowledge and the ability to save the students' face.

\section{$N L P$}

This factor which the researchers called NLP has 6 items. NLP is an approach to teaching and learning that can change learners' performance, it is also the knowledge of providing feedback and effective communication (Millroad, 2004). Items 2 and 61 refer to the teachers' knowledge of seeing human beings as human beings and make relationship with them and to help them develop their personality. Items 15, 29, 46, and 50 are to measure the teachers' ability of giving hints and prompts, helping the students to answer the questions, and in fact the ability to elicit the correct response.

\section{Students' self-esteem}

This eighth factor which has been called Students' Self-esteem consists of 2 items. Self-esteem is the individual's beliefs about his or her abilities and capacities as a person. Items 47 and 54 measure the teachers' awareness of this factor and the techniques that they use to restore learners self-esteem.

\section{Thinking}

The ninth factor that consists of 3 items has been called Thinking. This factor refers to items 9, 20 and 59 and tries to measure the teachers' ability to make the learners think and to raise consciousness in class and among students. All 
items refer to teachers' awareness of the techniques which relate language to thinking and also consciousness raising techniques.

FSA

This last factor which the researchers called FSA consists of 3 items. FSA refers to the acts that people should take to protect their own and other people's faces. Items 33 and 53 measure the teacher knowledge of these acts and his or her awareness of the necessity of saving the face of the learners. Item 37 refers to teachers' ability to save their own faces.

\section{Conclusion}

The purpose of this study was to substantiate the construct validity of ELT-CT which has been designed by Pishghadam et al. (2010). The value of this study lies in testing the claim of the test designer who validated the scale using Rasch analysis. In this study, we employed EFA to find out if the underlying factors of the test are what the test claims to be. The results have revealed that ten factors represent the underlying structure of ELT-CT. These factors were labeled as: Feedback \& flexibility, Teaching methodology, Learning boosters, Motivation, Sociology of language teaching \& learning, EQ, NLP, Students' self-esteem, Thinking and FSA.

The underlying factors of ELT-CT showed that the designed test can measure lots of different things and skills that a competent teacher should possess. The factors showed that the items of the test are from many different fields and can cover many different skills that a teacher should have.

It is our hope that future research will lead to further evaluation and improvement of this instrument. Researchers should continue to carry out thorough assessment of the psychometric properties of the instrument designed to measure language teacher competency. Only after the true factor structure of the ELT-CT instrument has been examined, can researchers confidently assert conclusions about the role of these variables in language learning.

In the end, researchers are recommended to examine objectively the relationship between ELT-CT and other related variables such as: teachers' characteristics, students' evaluation of their teachers, students' performance and success in class. These variables seem to be highly related to teacher cognition. Finding any association between these variables and teacher competency test helps us have a better understanding of the importance of this test.

\section{References}

Ahmadvand, M. (2004). How to become a reflective teacher. Foreign Language Teaching Journal, 83(21), 20-24

Baydala, L., Rasmussen, C., \& Sherman, J. (2004). The impact of teacher factors on acheivement and behavioural outcomes of children with Attention Deficit/Hyperactivity Drisorder (ADHD): a review of literature. Educational Research. 50(4).347-360

Bond, T.G., \& Fox, C.M. (2007). Applying the Racsh model: fundamental measurement in the human sciences. Lawrence Erlbaum. In Pishghadam, R. (2010). Validation of an English Language Teacher Competency Test. Unpublished manuscript.

Borg, S. (2003). Teacher cognition in language teaching: A review of research on what language teachers think, know, believe and do. Language Teaching, 36, 81-109

Brockman, G. (2010). Assessing teacher quality. CERA Newsletter, 4(1), 23-45

Brown, H. D. (2007). Teaching by principles: An interactive approach to language pedagogy. $\left(5^{\text {th }}\right.$ ed.). Pearson Education, Inc.

Dilmac, B. (2009). An analysis of teachers' general tendency to procrastinate, perception of professional efficacy/ self efficacy and altruism. Electronic Journal of Research in Educational Psychology, 7(3), 1323-1338

Dornyei, Z. (2005). The psychology of language learner. London: Lawrence Erlbaum Associates.

Hamdan, A. R., Ghafar, M. N., \& Hwe Li, L. T. (2010). Teacher competency testing among Malaysian school teachers. European Journal of Social Sciences, 12 (4), 610-617

Kagan, D. A. (1990). Ways of evaluating teacher cognition: Inferences concerning the Goldilockes principle. Review of Educational Research, 60(3), 419-469

Lowman, J. (1996). Characteristics of exemplary teachers. New Direction for Teaching and Learning, 65, 33-40

Mehrens, W. A. (1987). Validity issues in teacher licensure tests. Journal of Personnel Evaluation in Education. 1(2), 195-229

Millroad, R. (2004). The role of NLP in teachers' classroom discourse. ELT Journal, 58(1), 28-37 
Moyer-Packenham, P. S., Bolyard, J., Kitsantas, A., \& Oh, H. (2008). The assessment of mathematics and science teacher quality. Peabody Journal of Education, 83, 562-591

Pen-Edwards, S. (2010). The competencies of an English teacher: beginning student teachers' perceptions. Australian Journal of Education, 35(2), 49-66

Pettis, J. (2002). Developing our professional competence: Some reflections. Foreign Language Research, 54. 127-142.

Pishghadam, R., Baghaei, P., \& Shahriari, H. (2011). Development and validation of an English language teacher competency test. The International Journal of Educational and Psychological Assessment, 8(2), 54-68.

Rice, K. J. (2003). Teacher quality: understanding the effectiveness of teacher attributes. [Online] Available: http://www.epinet.org/content.cfm/books_teacher_quality_execsum_intro (June 21, 2007)

Strom, B., \& Tymofyeyev, R. (2004). Competency testing: general overview. White paper.

Swandee, A. (1995). Students' perceptions of university instructors' effective teaching characteristics. SLLT Journal, $5,6-22$

Table 1. Reliability of Each Factor

\begin{tabular}{lcc}
\hline Factors & Cronbach's Alpha & N of Items \\
\hline Factor 1 & .541 & 12 \\
Factor 2 & .620 & 6 \\
Factor 3 & .631 & 9 \\
Factor 4 & .678 & 9 \\
Factor 5 & .446 & 5 \\
Factor 6 & .502 & 4 \\
Factor 7 & .434 & 4 \\
Factor 8 & .385 & 2 \\
Factor 9 & .365 & 3 \\
Factor 10 & .503 & 4 \\
\hline
\end{tabular}


Table 2. KMO and Bartlett's Test

\begin{tabular}{|c|c|c|}
\hline \multicolumn{3}{|c|}{ KMO and Bartlett's Test } \\
\hline Kaiser-Meyer-Olkin Measu & of Sampling Adequacy & .434 \\
\hline \multirow[t]{3}{*}{ Bartlett's Test of Sphericity } & Approx. Chi-Square & $2.659 \mathrm{E} 3$ \\
\hline & $\mathrm{df}$ & 1830 \\
\hline & Sig. & .000 \\
\hline
\end{tabular}

Table 3. Rotation Method: Varimax with Kaiser Normalization

Rotated Component Matrix ${ }^{\mathrm{a}}$

\begin{tabular}{|c|c|c|c|c|c|c|c|c|c|}
\hline \multicolumn{10}{|c|}{ Component } \\
\hline 1 & 2 & 3 & 4 & 5 & 6 & 7 & 8 & 9 & 10 \\
\hline $48=.624$ & $41=.666$ & $58=.529$ & $57=.654$ & $28=.621$ & $5=.724$ & $2=.724$ & $47=.579$ & $9=.610$ & $53=.636$ \\
\hline $\begin{array}{l}25=.604 \\
7=.567 \\
23=.550 \\
26=.496 \\
19=.481 \\
6=.434 \\
27=.403 \\
32=.308 \\
18=.351 \\
17=.322 \\
11=.305 \\
49=.304\end{array}$ & $\begin{array}{l}42=.586 \\
31=.542 \\
44=.511 \\
24=.490 \\
60=.321\end{array}$ & $\begin{array}{l}35=.454 \\
3=.446 \\
1=.445 \\
45=.440 \\
38=.437 \\
52=.388 \\
51=.366 \\
8=.333\end{array}$ & $\begin{array}{l}10=.587 \\
14=.519 \\
55=.425 \\
56=.408 \\
43=.367 \\
22=.328 \\
36=.322 \\
40=.334\end{array}$ & $\begin{array}{l}4=.544 \\
21=.451 \\
30=.444 \\
12=.407 \\
34=.371\end{array}$ & $\begin{array}{l}13=.523 \\
16=.451 \\
39=.430\end{array}$ & $\begin{array}{l}15=.493 \\
61=.448 \\
29=.412 \\
46=.346 \\
50=.495\end{array}$ & $54=.310$ & $\begin{array}{l}59=.425 \\
20=.362\end{array}$ & $\begin{array}{l}37=.427 \\
33=.421\end{array}$ \\
\hline
\end{tabular}


Table 4. Ten factors of the test

\begin{tabular}{|c|c|c|c|}
\hline \# Areas & Statements & $\mathrm{N}$ of items & Percentage \\
\hline $\begin{array}{c}\text { Feedback\& } \\
\text { Flexibility }\end{array}$ & $6,7,11,17,18,19,23,25,26,27,32,48,49$ & 13 & 21 \\
\hline $\begin{array}{c}\text { Teaching } \\
\text { methodology }\end{array}$ & $24,31,41,42,44,60$ & 6 & 10 \\
\hline Learning boosters & $1,3,8,35,38,45,51,52,58$ & 9 & 14.7 \\
\hline Motivation & $10,14,22,36,40,43,55,56,57$ & 9 & 14.7 \\
\hline $\begin{array}{c}\text { Sociology of } \\
\text { language teaching } \\
\text { and learning }\end{array}$ & $4,12,21,28,30,34$ & 6 & 10 \\
\hline EQ & $5,13,16,39$ & 4 & 6.5 \\
\hline NLP & $2,15,29,46,50,61$ & 6 & 10 \\
\hline $\begin{array}{c}\text { Students } \\
\text { self-esteem }\end{array}$ & 47,54 & 2 & 3.2 \\
\hline Thinking & $9,20,59$ & 3 & 5 \\
\hline \multirow[t]{2}{*}{ FSA } & $33,37,53$ & 3 & 5 \\
\hline & Total & 61 & 100 \\
\hline
\end{tabular}

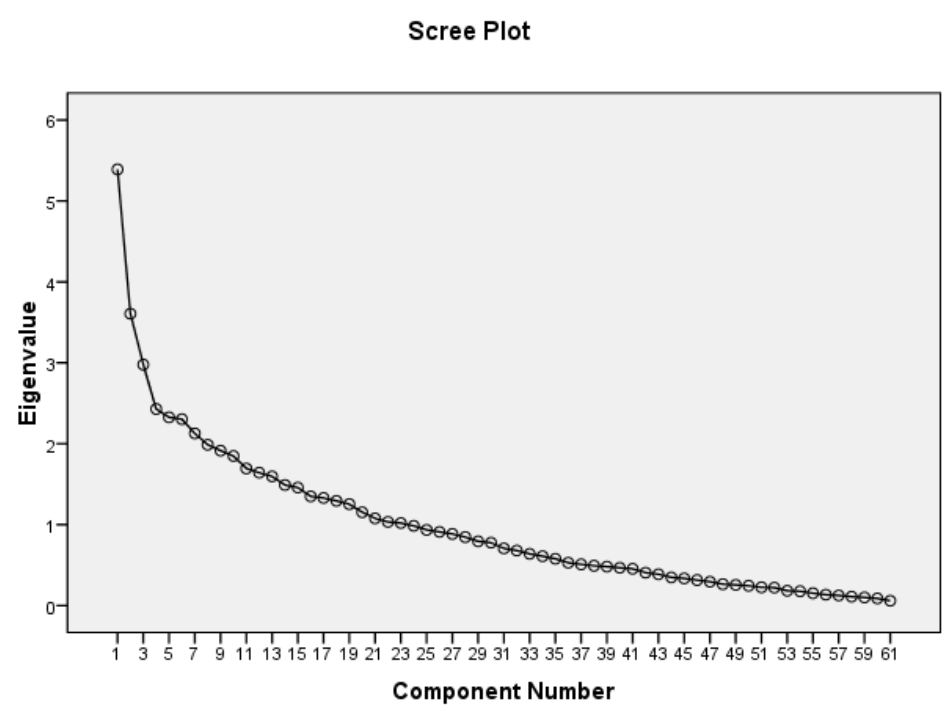

Figure 1. The Scree Test 


\section{Appendix The English Language Teacher Competency Test (ELT-CT)}

Full name:

Gender:

Years of teaching experience:
Age:

Degree:

University major :

Directions: For each of the items below, choose the best option by circling the letters a, b, c or d. The option you choose should be based on what you practice in the classroom, or believe to be the correct course of action. Please note that the teaching context in mind is a typical class held at a language institute.

1. Regarding the Persian language, I

a. never use it in my class.

b. I will use it if necessary.

c. try to teach through it.

d. force my learners not to use it in the class.

2. On the first session of the term,...

a. I introduce myself by giving my name and start the lesson immediately.

b. I introduce myself by giving my name and ask the students for theirs.

c. I talk about myself and then ask my students to tell me their names.

d. I talk about myself and then ask my students to talk about themselves too.

3 . The score I prefer to give my students is usually

a. out of 20 .

b. out of 100 .

c. ranging from $\mathrm{A}+$ to $\mathrm{F}$.

d. in the form of a remark, such as 'good' or 'excellent'.

4. During movie sessions, I

a. leave my students alone to enjoy the film.

b. stop each line of dialog and ask students to repeat what was said.

c. write down new words on the board as the movie is playing.

d. discuss the movie with my students in class and ask them to write a report on it.

5. If there are too many students in my class, I

a. ask my students for their names and try to address them by name as they speak.

b. avoid using names altogether.

c. address only those students whom I can remember by name.

d. address my students using humorous nicknames which I have given them.

6. Imagine it is the beginning of a term and you go to a class for the first time. Which of the following statements are you most likely to use?

a. "I'm allergic to using cell phones in my class."

b. "Those who don't study will receive low scores at the end of the term."

c. "To be successful in the course, I'd like you to conform fully."

d. "What are your expectations of the course?"

7. I begin each session of my class by

a. wasting no time and going directly to the new lesson.

b. telling my students what we are going to be doing on that session.

c. reviewing all that has been taught in the previous sessions.

d. checking to see whether the students have completed their homework. 
8. Considering my personal relationship with the learners, I

a. try to maintain a formal relationship both inside and outside the class.

b. sometimes disclose personal information about myself in the class.

c. try to foster an informal relationship all the time.

d. think there is no need to reveal any personal information about myself in the class.

9. In my opinion, one of the responsibilities of an English language teacher is to

a. convey information to the learner's mind.

b. relate language to thinking.

c. focus on the book being taught.

d. expose learners to the language being taught.

10. When speaking with students, which of the following statements is NOT appropriate to use?

a. "Give your reasons."

b. "What would you do if you were."

c. "What is your choice?"

d. "Do you understand my question?"

11. Imagine while you are teaching, one of your students suddenly laughs in the class. How would you react?

a. I would stop teaching for a while.

b. I would ignore it.

c. I might ask him/her to leave the class to make an example for other students.

d. I might frown at the learner in order to show how serious I am.

12. If a learner asks me a question, which I feel is intended to waste time, I will

a. first make sure if this is truly the learner's intention, then decide on what to do depending on my conditions and that of the class.

b. try to act strictly so as to set an example for any other student who may want to disrupt the order in my class.

c. avoid psychological tension in the class by simply reporting the student to the office to be properly dealt with.

d. ignore the problem and suppress any feeling of anger or resentment which I may have at the time.

13. With respect to my learners, I

a. think having eye contact with all students is not a must.

b. prefer to address my learners by name.

c. don't think knowing their names can help to control classroom activities.

d. prefer to have eye contact with more receptive and welcoming faces.

14. To heighten my learners' motivation, I

a. praise them all the time.

b. let them have some choices.

c. use scores as a kind of reward.

d. never correct their mistakes.

15. During a test, if all my students ask me for help on an item

a. I will give them the answer for encouragement.

b. I will not respond at all.

c. I will give them a clue to answering the question.

d. I will advise them to skip the item.

16. If a student does poorly on the final exam, I determine his/her score by

a. other tests and/or quizzes which I have taken during the term. 
b. his/her attendance during the course.

c. his/her performance on class activities and overall participation.

d. only his/her performance on the final.

17. When announcing the results of a test,

a. I will not mention the results at all.

b. I will give them their exam papers so that they can make sure they've been fairly assessed.

c. I will give them their exam papers and review the correct answers with the whole class.

d. I will not give them their exam papers until after the end of the term.

18. If a student of mine has problems in understanding a listening passage,,..

a. I repeat the passage as many times as necessary.

b. I explain what is being said, and repeat the passage once more.

c. I repeat the passage sentence by sentence myself until everything is made clear.

d. I explain pronunciation points heard in the passage, such as syllable reduction.

19. In my elementary classes, I improve my students' listening skill by...

a. asking them to listen to dialogs and then act them out.

b. giving them instructions and asking them to follow.

c. reading and speaking at a rate which is slower than natural speech.

d. asking them to listen and then discuss what was mentioned together.

20. Whenever I wish to present a reading passage to my class, I begin by...

a. reading the passage out loud for all the students to hear.

b. asking one of the students to read out the passage for all to hear.

c. providing definitions for unfamiliar words and expressions.

d. asking the students questions about the topic of the passage.

21. If a particular student in my class disagrees with the ideas expressed in a reading passage, I

a. try to persuade him that the author is right.

b. explain that he should probably read further and gain more knowledge on the topic.

c. put the writer's ideas up for discussion and allow the class to decide who's right.

d. explain that our job is to only understand what the passage says and not to deal with the ideas expressed.

22. If a student complains about a text having too many unfamiliar words, I

a. advise him to use a dictionary to look them up.

b. advise him not to use a dictionary and rely on guesswork.

c. advise him to choose another text altogether.

d. advise him to first guess, and then consult with a dictionary if necessary.

23. When an elementary-level student gives me a piece of writing, I

a. correct and comment on both the grammar errors and the ideas.

b. only comment on the ideas and how they are put into paragraphs.

c. only concern myself with the grammatical errors, misused words, punctuation, etc.

d. tell my student that he/she should wait a few terms before attempting to write.

24. When assigning homework for writing,

a. I give my students a different topic to write about each session.

b. I ask my students to write different types of passages each week (essays, letters, resumes, etc.).

c. I ask my students to complete a single writing assignment over the course of a few sessions, each time adding to its length. 
d. I give my students a single writing assignment which they will write and revise based on my notes and comments each week.

25. If my student does not use verbs in the past tense, but indicates that he is referring to the past by using other means such as adverbs of time,

a. I do not interfere so long as his message is understood.

b. I interfere every time he makes this mistake and correct him.

c. I remind him of his mistakes at the end of his turn.

d. I do not ask him to talk about the past until I'm ensured that he's able to do so.

26. With lower intermediate students, when choosing a topic for discussion in class,

a. I choose topics which are more likely to create a heated debate.

b. I allow my students to choose from the topics proposed by the textbook..

c. I stick to one of the topics proposed by the textbook.

d. I do not allow discussions in such classes at all.

27. If I have prepared myself to teach a given number of pages for a particular session, but I sense that the lesson is too tough for the students to handle, I

a. stick to my lesson plan despite the problems, because covering all materials is my first priority.

b. stick to my lesson plan despite the problems, and assign more homework to cover any weaknesses.

c. I slow down my pace and teach fewer pages of the lesson in more detail and practice.

d. I try to add more exercises and practice into the session without deviating from the plan.

28. If my students are experiencing problems learning new vocabulary items, I

a. will tell them all to use a single strategy like flashcards.

b. teach them the different ways of learning vocabulary and let them choose which one they prefer.

c. try to see which way is more common among the more successful students of the class and ask others to follow suit.

d. leave them alone to discover the right way to learn on their own.

29. If I teach the present perfect tense in class, I expect my students to

a. be able to talk about a variety of topics using the tense appropriately.

b. be able to make correctly formed sentences in response to questions I ask them.

c. be able to tell me the exact rule for making a sentence in the present perfect tense.

d. recognize any sentence which is in the present perfect tense.

30. When looking at my students in class, I

a. try to share my eye contact equally among all my students.

b. try to keep my eye contact with students who are listening carefully in order to maintain their attention.

c. try to keep my eye contact with students who are not listening carefully, so as to draw their attention to the class.

d. I do not pay conscious attention to my eye-contact.

31. If a student is showing problems completing a task in class, I try to place him

a. alone, so that I can observe him/her more carefully.

b. next to a more capable student, so that he/she can improve through interacting with him/her.

c. next to other students with a low achievement, so that he/she is not discouraged.

d. wherever he was situated before, without disrupting class order.

32. Whenever a students of mine asks me a question in Farsi, I

a. punish them by requiring them to put money into a jar.

b. allow it as long as they repeat their question in English with my help. 
c. allow it as long as they were truly unable to say what they meant in proper English.

d. ignore their question, and ask them to wait until the end of the class to ask.

33. When selecting authentic materials, such as a newspaper article, to present in class, I only choose articles which

a. contain information that is new and interesting for the students.

b. contain grammar and vocabulary studied in class.

c. have familiar topics and are easy to understand.

d. are randomly chosen from one of the most famous English newspapers.

34. During a classroom conversation, if a student manages to convey his/her messages through English words with a Farsi word order, I

a. allow him/her to continue so long as he/she is understood.

b. try to prevent him/her from further participation in the discussion.

c. stop him/her every time a mistake is made.

d. repeat what that student is saying with the correct word order.

35. When determining deadlines for handing in assignments, I

a. negotiate the deadline and often postpone it upon my students' request.

b. negotiate the deadline, but never postpone it once it has been set.

c. assign the deadline myself, but postpone it upon request.

d. assign the deadline myself and never postpone it once it has been set.

36. If a student of mine does not show interest in learning English, I

a. will tell him/her all about the British and American culture and way of life

b. will encourage him/her to watch movies and listen to music in English.

c. will tell him/her how English could be useful in one's future life and career.

d. will try to discover his/her interests and relate how English could be of use.

37. If I happen to make a mistake in a children's class, I

a. admit to it and use it to show that making mistakes is a normal part of learning.

b. ignore it, because I want to keep my credibility and respect among my learners.

c. pretend that I had made the mistake on purpose in order to teach my students a lesson.

d. ignore the mistake, but later in the lesson, teach the correct form.

38. To prevent students from being frequently absent in my classes, I tend to

a. reward students who are not absent at all with additional marks.

b. take away marks from those students who exceed a certain number of absences.

c. take matters to the management of the institute or school at which I work.

d. ignore those students who are frequently absent in my classes.

39. If I criticize a student in class and he/she feels disheartened by what I have said,

a. I try to praise the student publicly, in order to help him/her regain self-esteem.

b. I offer my formal apologies privately after the session is over.

c. I offer my formal apologies publicly in front of the whole class.

d. I try not to pay too much attention until the feelings go away.

40. In my classes, spontaneous bursts of laughter

a. are welcome since they are signs of how energetic my students are.

b. are welcome since they can be used to show other teachers how much fun we are experiencing in our class.

c. are unwelcome since they often lead to disorderly behavior in class.

d. are unwelcome since they suddenly alter the dominant mood of the class. 
41. With advanced level students, when choosing a topic for discussion in class, I

a. sometimes choose topics which are somewhat controversial, in order to encourage interaction and authentic debates.

b. always choose topics which have been proposed by the textbook because they are more appropriate and less likely to be offensive.

c. always allow my students to choose whatever topic they desire.

d. try to avoid controversial topics, because these may lead to heated debates which may not be possible to handle.

42. If students are making a lot of noise in my class and are not listening to me, I

a. speak in a louder volume to get their attention.

b. bang my fist on the desk to get their attention.

c. leave the class as a sign of protest.

d. remain silent until they quiet down and start paying attention.

43. When a student asks me about the meaning of a word, I explain it through

a. providing the dictionary definition

b. using the word in an example

c. miming the word or using pictures

d. a different technique each time

44. In a crowded classroom, when conducting a discussion, I

a. divide the class into groups and ask each group to report their ideas to the class.

b. divide the students into pairs and ask them to discuss the topic at hand.

c. ask each student to express his/her ideas very briefly.

d. allow the students to choose whether to speak or remain silent.

45. Having assigned group work, if a particular group finishes sooner than others, I

a. ask them to complete the task for a second time.

b. ask them to complete a follow-up to the task.

c. ask them to wait until other groups also finish.

d. ask them to go around helping members from the other groups.

46. During a classroom discussion, if a student has nothing to say regarding the topic, I

a. stop the discussion until he/she finds something to say.

b. force him/her to say something by taking away class points or marks.

c. leave the student alone until he/she is ready to say something.

d. try to ask the question in different ways to help him/her come up with ideas.

47. When a student does poorly on an examination, I am more likely to say

a. better luck next time.

b. I know the exam was so difficult.

c. you should have tried harder.

d. you may not be fit for the course.

48. If a student has a kind of Persian accent while speaking, I .

a. make him/her achieve a kind of British accent.

b. ask him/her to mimic the American accent.

c. won't push him/her to mimic any native-like accent.

d. ask him/her to work more on his/her accent.

49. If a student drops the third person's from a verb, I 
a. correct his/her mistake immediately.

b. correct his/her mistake at the end of the session.

c. ignore it.

d. notice closely to see whether s/he makes the same mistake again.

50. If a learner has a problem with his/her learning, I

a. help him/her directly by giving prompts to solve the problem.

b. just facilitate the process of learning.

c. make him/her discover the solution by him/herself.

d. ask him/her to cooperate with his/her friends to solve it.

51. To enhance critical thinking in my learners, I prefer to start my questions with terms like

a. rate, defend

b. define, tell

c. locate, match

d. arrange, separate

52. Regarding teaching methodology, I

a. try to find the best methods for teaching.

b. prefer to use one method of teaching for all of my classes to ensure consistency.

c. will be flexible in using different methods.

d. try to model the methods which I think are the best.

53. When I pose a question in the class, I

a. give the learners some time to think before answering the question.

b. ask them to answer it quickly for the task to be more 'real life'.

c. try to change it into a yes/no question to make it easier for the learners to answer.

d. add more questions to make the learners have more interaction.

54. If a learner receives a good score on an examination, I would probably say

a. You must be really smart.

b. Surly, you have studied hard.

c. You are so lucky.

d. The exam was easy for you.

55. If I give a test of language aptitude to one of my learners and s/he receives low score on it, I may say to her/him

a. It's better to drop studying the English language.

b. Don't worry. You should practice harder.

c. It is not your fault. Aptitude is something that nobody can change.

d. You can learn English, but slowly.

56. Imagine you are teaching kids. One of them asks you the Persian equivalent of a word that you don't know. What would you say?

a. Sorry. I don't know.

b. It is not a good time to ask questions.

c. Very good. This is exactly what I wanted you to look up for the next session.

d. I should have a look at a dictionary.

57. If one of your learners says I think you are wrong. What is the most probable feedback which you may provide?

a. That's interesting. In what way?

b. I think you will find that all of the studies show this to be true. 
c. I think you need more time to understand that you are wrong.

d. No problem. This is your opinion.

58. Regarding activities in the classroom, which of the following is NOT appropriate to do in class?

a. Instead of distributing handouts, place them in three or four piles around the room and ask everyone to collect one.

b. Asking learners to walk and talk while carrying out any brief activity in pairs.

c. When learners are forming groups, asking them to find one or two others who are not sitting next to them.

d. To maintain discipline, learners should not be allowed to move in class.

59. Considering teaching grammar, I

a. never teach it to be natural.

b. try to teach English through grammar.

c. try to make the learners conscious of some forms.

d. think it must be at the forefront of the class.

60. Considering teaching skills, I believe that

a. teaching each skill in isolation is practical and useful.

b. teaching different skills must be done in combination.

c. students must mimic sample models of the English language.

d. focus must be on the forms of language.

61. With respect to teaching culture, I

a. give more priority to the English culture in the class.

b. highlight the Persian culture more than the English one.

c. do not teach the English culture directly.

d. focus on the English culture to make learners become native-like. 